\title{
Partial sequencing of recent Portuguese myxoma virus field isolates exhibits a high degree of genetic stability
}

\author{
A. Muller ${ }^{\mathrm{a}, \mathrm{b}, *}$, E. Silva ${ }^{\mathrm{a}, \mathrm{b}}$, J. Abrantes ${ }^{\mathrm{c}, \mathrm{d}, \mathrm{h}, \mathrm{i}}$, P.J. Esteves ${ }^{\mathrm{c}, \mathrm{e}}$, P.G. Ferreira ${ }^{\mathrm{f}}$, J.C. Carvalheira ${ }^{\mathrm{a}, \mathrm{c}}$, \\ N. Nowotny ${ }^{g}$, G. Thompson ${ }^{\mathrm{a}, \mathrm{b}}$ \\ ${ }^{a}$ Department of Veterinary Clinics, Institute of Biomedical Science Abel Salazar (ICBAS), University of Porto, P-4099-003 Porto, Portugal \\ ${ }^{\mathrm{b}}$ Multidisciplinary Unit of Biomedical Investigation (UMIB), University of Porto, P-4099-003 Porto, Portugal \\ ${ }^{\mathrm{c}}$ Centre of Investigation for Biodiversity and Genetic Resources (CIBIO), University of Porto, P-4485-661 Vairão, Portugal \\ ${ }^{\mathrm{d}}$ Department of Zoology and Anthropology, Faculty of Sciences, University of Porto, P-4150-150 Porto, Portugal \\ e Centro de Investigação em Tecnologias da Saúde (CITS), CESPU, Portugal \\ ${ }^{\mathrm{f}}$ Department of Anatomy, Institute of Biomedical Science Abel Salazar (ICBAS), University of Porto, P-4099-003 Porto, Portugal \\ ${ }^{\mathrm{g}}$ Zoonoses and Emerging Infections Group, Clinical Virology, Department of Pathobiology, University of Veterinary Medicine, Vienna, A-1210 Vienna, Austria \\ h INSERM, U892, Nantes, France \\ ${ }^{\text {i } U n i v e r s i t e ́ ~ d e ~ N a n t e s, ~ F r a n c e ~}$
}

\section{A R T I C L E I N F O}

\section{Article history:}

Received 20 March 2009

Received in revised form 14 July 2009

Accepted 31 July 2009

\section{Keywords:}

Myxoma virus

Field strains

Sequence analysis

Co-evolution

European rabbit

\begin{abstract}
A B S T R A C T
To study genetic changes underlying myxoma virus evolution in its new host, the European rabbit (Oryctolagus cuniculus), we sequenced selected genomic regions of nine recent virulent field strains and a live attenuated vaccine strain ("MAV", Germany). DNA was extracted from cell culture passaged myxoma virus. A total of $4863 \mathrm{bp}$ (approximately $3 \%$ of the genome) of 10 regions spanning 12 genes of the myxoma viruses was sequenced and compared to the original virulent strain "Lausanne" and its attenuated field derivative strain "6918". The field strains displayed a maximum of three (strains C43, C95) and a minimum of one (strains CD01, CD05) nucleotide substitutions. These were distributed through all analysed coding regions, except gene M022L (major envelope protein), where all strains were identical to "Lausanne" and "6918". Two new single nucleotide insertions were observed in some of the field strains: within the intergenic region M014L/M015L and within gene M009L, where it leads to a frameshift. These insertions were located after homopolymeric regions. The vaccine strain displayed 37 nucleotide substitutions, predominantly (95\%) located in genes M022L and M036L. Interestingly, regions M009L and M014L/M015L of the vaccine were not amplified successfully, suggesting major genomic changes that could account for its attenuated phenotype. Our results support a high degree of genetic stability of myxoma virus over the past five decades. None of the analysed genome regions by its own seems sufficient for the genetic characterisation of field strains.
\end{abstract}

(c) 2009 Elsevier B.V. All rights reserved.

\section{Introduction}

Myxoma virus (MV) is a large double stranded-DNA virus of the genus Leporipoxvirus. In its natural hosts (Sylvilagus

\footnotetext{
* Corresponding author at: ICAV-UP, Rua Padre Armando Quintas, 4485-661 Vairão, Portugal. Tel.: +351 252 660410; fax: +351 252661780.

E-mail address: amuller@mail.icav.up.pt (A. Muller).
}

brasiliensis and Sylvilagus bachmani) it causes benign cutaneous fibromas. However, its introduction in the 1950s into a new host, the European rabbit (Oryctolagus cuniculus), resulted in devastating epizootics with mortality rates above $99 \%$. Interestingly, within a few years of the introduction of the virus into naïve European wild rabbit populations in Australia and Europe, a decrease from the initial nearly $100 \%$ mortality rates were observed. This process has been related to virus-host adaptation consisting 
of the evolution of attenuated viral strains and the natural selection of resistant rabbits (reviewed by Fenner and Ross, 1994). Extensive knowledge has been gained on subjects related to this co-evolution, such as the determination of virulence grades of circulating myxoma viruses (e.g. Bárcena et al., 2000; Fenner and Ross, 1994; Marlier et al., 1999), the pathogenesis of myxoma virus infection of different clinical outcomes (Best and Kerr, 2000; Best et al., 2000), the rabbits' immune response (reviewed by Fenner and Ross, 1994), and the characterisation of virally encoded proteins able to modulate the host's immune response and thus clinical outcome of infection (e.g. Johnston and McFadden, 2003; Stanford et al., 2007; Willer et al., 1999; Zúñiga, 2002). Contrasting little is known about the genetic changes related to the evolution of myxoma virus in its new host (Kritas et al., 2008; Morales et al., 2008; Saint et al., 2001). The evolution of poxviruses has been studied based on whole-genome phylogenetic analyses rather than single gene phylogeny due to the occurrence of phenomena such as horizontal gene transfer (Bratke and McLysaght, 2008; Gubser et al., 2004; Hughes and Friedmann, 2005; Xing et al., 2006). To date, the complete genomes of only two myxoma viruses are available: the virulent strain "Lausanne", introduced in 1952 in Europe, and its attenuated field derivative "6918", obtained in 1995 in Spain (Bárcena et al., 2000; Cameron et al., 1999; Morales et al., 2008). The comparative analysis of both genomes has identified 73 differences consisting of 67 base substitutions, 4 deletions and 2 insertions (Morales et al., 2008). Interestingly, events such as whole gene loss or gain were not observed.

The understanding of genetic changes driving myxoma virus evolution in the European rabbit requires the genetic analysis of larger numbers of field strains. The large size of the viral genome has hampered the availability of this kind of information, and partial gene sequences have shown little if any differences compared to the virulent strain Lausanne (Kritas et al., 2008; Saint et al., 2001). As gene order and content remained unchanged in the attenuated myxoma virus field strain "6918" (Morales et al., 2008), it may be sufficient to study virus evolution by analysing specific genomic regions. Our objectives were to study selected genomic regions of recent myxoma virus field isolates and to evaluate the suitability of these as molecular marker for virus evolution within the European rabbit.

\section{Materials and methods}

\subsection{Selection of viral genes}

The genome comparison between the virulent myxoma virus strain "Lausanne" (GenBank accession no. AF170726) and the attenuated field strain "9618" (GenBank accession no. AF552530), suggested that the observed disruptions in ORFs M135R, M148R, M009L, M036L may be related to loss of viral virulence (Morales et al., 2008). Thus, we included these genome regions in our analysis (Table 1). We also partially amplified gene M020L to confirm the insertion of the CTC codon for leucine at position 52 (Morales et al., 2008). Further five viral genome regions were selected, which include the following partial genes: M002L/R and $\mathrm{M} 007 \mathrm{~L} / \mathrm{R}$ for being located in the terminal inverted repeats

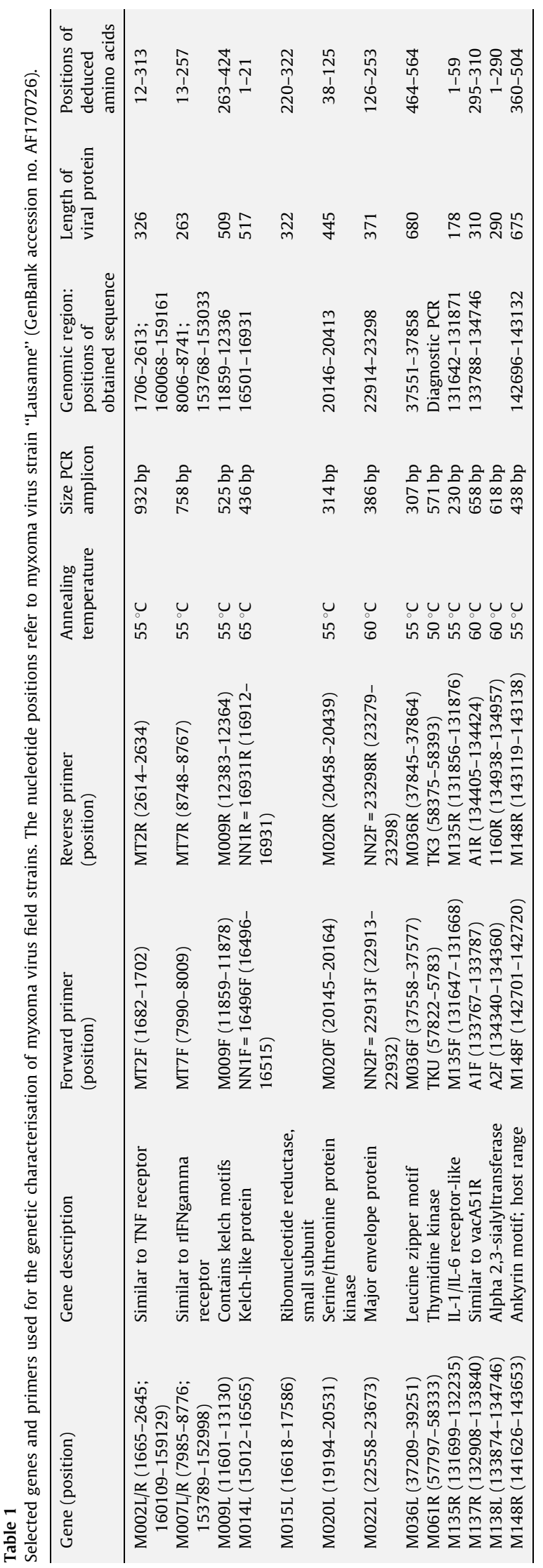


and encoding immunomodulatory proteins similar to TNF receptor and to rIFN gamma receptor, respectively (Johnston and McFadden, 2003; Stanford et al., 2007; Willer et al., 1999), M014L and M015L, which encode a kelch-like protein and the small subunit of ribonucleotide reductase, respectively; M022L encoding the major envelope protein, as this protein is exposed to the immune system of the host, and may reflect the effect of immune pressures; M137R and M138L because the corresponding sequence of the California myxoma virus strain "MSD" (GenBank accession no. AF030894) was available for comparison and displayed major differences when compared with "Lausanne" (Jackson et al., 1999). The "MSD" strain naturally infects the brush rabbit (S. bachmani) but causes fulminant disease in the European rabbit. A further locus, M061R, coding for the thymidine kinase gene, was selected for diagnostic purposes only (see below). The term "genomic region" was used to describe the amplified sequences, which correspond to either part of a single gene, or, in the case of M014L/M015L and M137R/M138R, to two adjacent genes and their respective intergenic noncoding region.

\subsection{Primers and sequencing}

The targeted genes and used primers are shown in Table 1. A hot start Taq polymerase (Hotstar Taq Polymerase, Qiagen) was used. The annealing conditions of the PCR reactions varied between 50 and $65^{\circ} \mathrm{C}$. The PCR products were directly sequenced in both directions. The obtained sequences were edited, aligned and analysed using the software Bioedit (Hall, 1999). The obtained sequences were compared to sequences available in GenBank by performing BLAST searches. The deduced amino acid sequences were compared to the proteins of myxoma virus strain "Lausanne" and "6918".

\subsection{Myxoma virus isolates}

Nine field strains were obtained from European rabbits displaying signs and/or lesions compatible with myxomatosis. They were collected between 2004 and 2007 in different locations in Portugal: four were obtained from wild rabbits in the southern province Algarve (C43, C95, C116, C152), three from wild rabbits in the north-eastern province Trás-os-Montes e Alto Douro (CB31, CB32, CB191), and two from an outbreak in domestic rabbits in the north-western province Douro Litoral (CD01, CD05). The vaccine strain "MAV" was originally derived from a cell culture attenuated Californian myxoma MSD virus (Mckercher and Saito, 1964). It is currently used as seed for commercially available vaccines in Europe (Gorski et al., 1994). This vaccine strain was kindly made available by the company IDT Biologika GmbH, Dessau, Germany, through the Friedrich-Loeffler-Institut, Germany, and was used here as reference strain.

The diagnosis of myxomatosis was made by PCR targeting the thymidine kinase gene (M061R) using DNA extracts from eyelids (Table 1). In order to increment viral yield for the genetic characterisation, the viruses were passaged twice in RK-13 cells. Virus was harvested after submitting the infected cell culture twice to freeze-thaw cycles at $-80^{\circ} \mathrm{C}$. Cell-free supernatant was used for nucleic acid extraction using the QIAamp Viral RNA Mini Kit (Qiagen, Hilden, Germany) according to the manufacturer's instructions.

\subsection{Nucleotide sequence accession numbers}

The GenBank accession numbers of 16 sequences representing the observed nucleotide changes are FJ970492-FJ970507.

\section{Results}

Ten genomic regions spanning 12 genes were selected for the partial genetic analysis of 9 virulent myxoma virus field isolates obtained from 7 wild and 2 domestic rabbits between 2004 and 2007 in Portugal, as well as from the German live attenuated vaccine strain "MAV". The sequence information on 4863 bp (corresponding to $3 \%$ of the viral genome) was compared to that of strains "Lausanne" and "6918". We also confirmed the insertion of the CTC codon in gene M020L of all field strains as well as the vaccine strain (data not shown). The results are shown in Table 2. Within gene M002L/R (907 bp) all field isolates displayed one single nucleotide substitution, albeit at three different locations. Six of the nine field strains displayed a nonsynonymous substitution at position 1981, which was also observed in strain "6918". The field strains CB191 and CD01 showed a synonymous substitution at position 1971. In field strain CD05, which originated from the same outbreak as CD01, a nonsynonymous nucleotide change at a different position (1975) was observed. The vaccine strain was identical to "Lausanne". Within gene M007L/R (735 bp), two nonsynonymous nucleotide substitutions were observed in field strain C43 and in the vaccine strain (positions 8261 and 8494, respectively). Within gene M009L (477 bp), five field strains (C95, C116, CB31, CB32, CB191) displayed a single nucleotide insertion (C) at position 12297 after a homopolymeric region of 5 cytosins, causing a frameshift after amino acid 280 . The PCR amplification of the vaccine strain yielded two very weak bands of approximately 100 and $400 \mathrm{bp}$, inadequate for successful sequencing. Within the region spanning M014L/M015L (430 bp) a single nucleotide insertion (A) was observed at position 16616 of the intergenic region of six field strains (C43, C95, C116, CB31, CB32, CB191) after a homopolymeric region of 10 adenosines. PCR amplification of this region of the vaccine strain was unsuccessful. At gene M022L (384 bp) all field strains were identical to "Lausanne" and the vaccine strain displayed eight synonymous nucleotide substitutions. Within gene M036R (229 bp), nonsynonymous nucleotide substitutions were observed at positions 37588 and 37759, of the two field strains C95 and C152, respectively. The vaccine strain displayed 27 nucleotide substitution, of which 5 were nonsynonymous. In gene M135R (229 bp), the same nonsynonymous nucleotide substitution was observed at position 131772 in the field strains CB31 and CB32. The remaining, as well as the vaccine strain, were identical to "Lausanne". Within the region spanning M137R/138L 


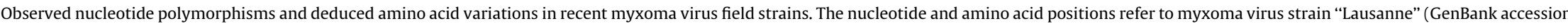
no. AF170726). The GenBank accession numbers of selected sequences (FJ970492-FJ970507) are indicated below the respective polymorphic nucleotide positions.

\begin{tabular}{|c|c|c|c|c|c|c|c|c|c|c|c|c|c|c|c|c|c|}
\hline \multirow{3}{*}{ Gene } & \multicolumn{6}{|c|}{ Terminal region } & \multicolumn{9}{|c|}{ Central region } & \multirow{2}{*}{\multicolumn{2}{|c|}{$\begin{array}{l}\text { Terminal region } \\
\text { M148R } 436 \text { bp }\end{array}$}} \\
\hline & \multicolumn{2}{|c|}{ M002L/R 907 bp } & \multicolumn{2}{|c|}{ M007L/R 735 bp } & \multicolumn{2}{|c|}{ M009L 477 bp } & \multirow{2}{*}{$\begin{array}{l}\text { M014L } \\
\text { M015L } \\
430 \text { bp } \\
\text { NT }\end{array}$} & \multicolumn{2}{|c|}{ M022L 384 bp } & \multicolumn{2}{|c|}{ M036L 307 bp } & \multicolumn{2}{|c|}{ M135R 229 bp } & \multicolumn{2}{|c|}{$\begin{array}{l}\text { M137R/M138L } \\
958 \mathrm{bp}\end{array}$} & & \\
\hline & NT & $\mathrm{AA}$ & NT & AA & NT & $\mathrm{AA}$ & & NT & AA & NT & $\mathrm{AA}$ & NT & AA & NT & AA & NT & $\mathrm{AA}$ \\
\hline $\begin{array}{l}\text { Strain } 6918 \\
\quad(\text { EU552530) }\end{array}$ & $\begin{array}{l}\text { T1981 } \\
\text { A2497 } \\
\text { T2594 }\end{array}$ & $\begin{array}{l}\text { D222 } \\
\text { F104 } \\
\text { S18 }\end{array}$ & A8064 & F238 & $\begin{array}{l}\text { Deletion } \\
11942- \\
11951\end{array}$ & $\begin{array}{l}\text { F/S after } \\
\text { aa395 } \\
\text { start Met } \\
398\end{array}$ & ID & ID & ID & $\begin{array}{l}\text { Insertion } \\
\text { C37687 }\end{array}$ & $\begin{array}{l}\text { F/S after } \\
\text { aa523 } \\
\text { start Met } \\
542\end{array}$ & $\begin{array}{l}\text { Insertion } \\
\text { G131750 }\end{array}$ & $\begin{array}{l}\text { F/S } \\
\text { after aa } 19 \\
\text { start Met } \\
44\end{array}$ & ID & ID & $\begin{array}{l}\text { Deletionl } \\
\text { C142959 }\end{array}$ & $\begin{array}{l}\text { F/S after } \\
\text { aa446 } \\
\text { start Met } \\
505\end{array}$ \\
\hline C43 & $\begin{array}{l}\text { T1981 } \\
\text { FJ970494 }\end{array}$ & D222 & $\begin{array}{l}\text { A8261 } \\
\text { FJ970496 }\end{array}$ & ID & ID & ID & $\begin{array}{l}\text { ID }^{\mathrm{a}} \\
\text { FJ970498 }\end{array}$ & ID & ID & ID & ID & ID & ID & ID & ID & $\begin{array}{l}\text { G142867 } \\
\text { FJ970506 }\end{array}$ & S416 \\
\hline C95 & T1981 & D222 & ID & ID & $\begin{array}{l}\text { Insertion } \\
\text { C12297 } \\
\text { FJ970497 }\end{array}$ & $\begin{array}{l}\text { F/S after } \\
\text { aa280 } \\
\text { start Met } \\
303\end{array}$ & $\mathrm{ID}^{\mathrm{a}}$ & ID & ID & $\begin{array}{l}\text { T37588 } \\
\text { FJ970500 }\end{array}$ & M496 & ID & ID & ID & ID & G142867 & S416 \\
\hline C116 & T1981 & D222 & ID & ID & $\begin{array}{l}\text { Insertion } \\
\text { C12297 }\end{array}$ & $\begin{array}{l}\text { F/S after } \\
\text { aa280 } \\
\text { start Met } \\
303\end{array}$ & $\mathrm{ID}^{\mathrm{a}}$ & ID & ID & ID & ID & ID & ID & ID & ID & G142867 & S416 \\
\hline C152 & T1981 & D222 & ID & ID & ID & ID & ID & ID & ID & $\begin{array}{l}\text { T37759 } \\
\text { FJ970501 }\end{array}$ & M553 & ID & ID & ID & ID & ID & ID \\
\hline СВ31 & T1981 & D222 & ID & ID & $\begin{array}{l}\text { Insertion } \\
\text { C12297 }\end{array}$ & $\begin{array}{l}\text { F/S after } \\
\text { aa280 } \\
\text { start Met } \\
303\end{array}$ & $\mathrm{ID}^{\mathrm{a}}$ & ID & ID & ID & ID & $\begin{array}{l}\text { T131772 } \\
\text { FJ970503 }\end{array}$ & $\mathrm{C} 27$ & $\begin{array}{l}\text { ID }^{\mathrm{b}} \\
\text { FJ970504 }\end{array}$ & ID & ID & ID \\
\hline CB32 & T1981 & D222 & ID & ID & $\begin{array}{l}\text { Insertion } \\
\text { C12297 }\end{array}$ & $\begin{array}{l}\text { F/S after } \\
\text { aa280 } \\
\text { start Met } \\
303\end{array}$ & $\mathrm{ID}^{\mathrm{a}}$ & ID & ID & ID & ID & $\mathrm{T} 131772$ & $\mathrm{C} 27$ & $\mathrm{ID}^{\mathrm{b}}$ & ID & ID & ID \\
\hline CB191 & $\begin{array}{l}\text { T1971 } \\
\text { FJ970492 }\end{array}$ & ID & ID & ID & $\begin{array}{l}\text { Insertion } \\
\text { C12297 }\end{array}$ & $\begin{array}{l}\text { F/S after } \\
\text { aa280 } \\
\text { start Met } \\
303\end{array}$ & $\mathrm{ID}^{\mathrm{a}}$ & ID & ID & ID & ID & ID & ID & $\begin{array}{l}\text { A133966 } \\
\text { FJ970505 }\end{array}$ & C261 & ID & ID \\
\hline CD01 & T1971 & ID & ID & ID & ID & ID & ID & ID & ID & ID & ID & ID & ID & ID & ID & ID & ID \\
\hline CD05 & $\begin{array}{l}\text { C1975 } \\
\text { FJ970495 }\end{array}$ & G224 & ID & ID & ID & ID & ID & ID & ID & ID & ID & ID & ID & ID & ID & ID & ID \\
\hline $\begin{array}{l}\text { Vaccine strain } \\
\text { "MAV" }\end{array}$ & ID & ID & $\begin{array}{l}\text { G8492 } \\
\text { FJ970507 }\end{array}$ & ID & $\begin{array}{l}\text { No PCR } \\
\text { amplicon } \\
\text { ( } 2 \text { weak } \\
\text { bands } 100+ \\
400 \mathrm{~kb} \\
\text { approx.) }\end{array}$ & - & $\begin{array}{l}\text { No PCR } \\
\text { amplicon }\end{array}$ & $\begin{array}{l}\text { C23296 } \\
\text { T23212 } \\
\text { C23218 } \\
\text { A23235 } \\
\text { C23236 } \\
\text { G23254 } \\
\text { T23257 } \\
\text { FJ970499 }\end{array}$ & All ID & $\begin{array}{l}27 \text { nt subst. } \\
\text { FJ970502 }\end{array}$ & $\begin{array}{l}\text { L458 } \\
\text { S491 } \\
\text { S530 } \\
\text { S532 } \\
\text { S549 } \\
\text { All other } 22 \\
\text { ID }\end{array}$ & ID & ID & ID & ID & $\begin{array}{l}\text { T142804 } \\
\text { FJ970493 }\end{array}$ & V395 \\
\hline
\end{tabular}

a Insertion (A) after nucleotide 16616 of a poly-A in the non-coding region.

${ }^{b}$ Point mutation $(\mathrm{C} \rightarrow \mathrm{T})$ at position 133846 in the non-coding region. 
(958 bp), a nonsynonymous nucleotide substitution was observed at position 133966 of field strain CB191, and a single nucleotide substitution at position 133846 in the intergenic non-coding region of strains CB31 and CB32. Within gene M148R (436 bp), nonsynonymous nucleotide substitutions were observed at position 142867 of isolates C43, C95, C116, and at position 142804 of the vaccine strain.

\section{Discussion}

Since the introduction of Myxoma virus into its new host population, the European rabbit, a decrease in disease mortality has been observed and myxomatosis has turned into a frequently cited example of virus-host adaptation, but genetic information on field strains is scarce (Kritas et al., 2008; Morales et al., 2008; Saint et al., 2001). In the present study only virulent virus strains were included, because field evidence of attenuated or atypical forms of disease is difficult to obtain, as these probably go undetected, e.g. we were unable to find evidence of myxoma virus infection in eyelid samples from 30 healthy wild rabbits hunted in southern Portugal (Pancas) and tested by PCR analysis of the TK gene as well as by three consecutive passages on RK-13 cells (data not shown). The analysed nucleotide sequences presented here corresponded to only approximately $3 \%$ of the complete viral genome, but they were selected based on the abovementioned criteria and thus considered good candidates for detecting changes reflecting virus-host co-evolution. Interestingly, a maximum of only three (strains C43, C95) and a minimum of one nucleotide substitutions (strains CD01, CD05) were observed in each field strain. The attenuated strain "6918" only displayed four nucleotide substitutions within the analysed genome regions, one of which (position 1981 of gene M002L/R) was also found in six of the field strains, suggesting that this mutation is being fixed in some European wild rabbit populations. The major envelope gene (M022L) of myxoma is exposed to the rabbit's immune system, and expected to be a good target for identifying viral variability. Surprisingly, the analysed gene sequences of the field isolates were identical to strain "Lausanne", similar to that of a pathogenic myxoma virus isolated from an outbreak in vaccinated and non-vaccinated commercial rabbits in Greece (Kritas et al., 2008). Within M022L of the vaccine strain, eight synonymous nucleotide substitutions were found. No equivalent sequence information on the MSD strain was found in GenBank to understand whether these mutations are characteristic for this strain, or whether they may reflect pressures related to its attenuation process. Although our findings support the limited degree of genetic alteration found in recent myxoma virus field strains (Morales et al., 2008; Saint et al., 2001), the mutations observed in the selected genome regions allowed the individual identification and some grouping of the strains according to their geographic origin. For example, CB31 and CB32, which were collected from wild rabbits during the same occasion, are identical to each other but differ from CB191, which was sampled at a different geographic location, but also in the north of Portugal. Interestingly the strains obtained from domestic rabbits during an outbreak in a family farm (CD01, CD05) displayed mutations at different locations of gene M002L/R, but were otherwise identical to "Lausanne".

Within myxoma viruses, whole gene gain or loss does not seem to occur, but single or multiple base pair insertions and deletions which resulted in frameshift mutations have been described (Morales et al., 2008). We have found two homopolymeric sites, where a single nucleotide has been inserted in some of the virulent field strains: within gene M009L and in the non-coding region between M014L and M015L. Thus these single nucleotide insertions do not seem to affect virulence. However, major disruptions, at least in M009L, may indeed play an important role in attenuation, e.g. in strain "6918" (Morales et al., 2008). Although it has been argued that integrity of gene M009L may not be a critical virulence factor in myxoma virus, because of its disruption in the virulent Californian strain MSW (Labudovic et al., 2004) and its partial duplication in the attenuated Shope fibroma virus (Willer et al., 1999), it should be remembered, however, that these leporipoxviruses have evolved in different hosts, S. bachmani and S. floridanus, respectively, whereas the natural host of myxoma virus is $S$. brasiliensis (Fenner and Ross, 1994). They present a considerable degree of genetic heterogeneity (84-89\%) and may not entirely be suitable for comparison with "Lausanne" and "6918". Major changes are likely to be present in gene M009L of the vaccine strain, hampering PCR amplification and yielding two products of smaller sizes. The use of two other primer pairs overlapping the site of the deletion in "6918" (positions 11937-11947) was unsuccessful (not shown). The region spanning genes M014L/M015L of the vaccine strain could also not be amplified successfully, suggesting the occurrence of genomic changes requiring further investigations. Single indels in genes M135R and M148R were considered of putative relevance for the attenuation of "6918" (Morales et al., 2008). Our results support this hypothesis as these changes were not observed in the virulent field strains. However, they were neither found in the vaccine strain, indicating that they are not essential for attenuation. The disruption of another gene (M135R) was considered a potentially important determinant for the attenuation of the field strain "6918" (Morales et al., 2008). Again, this disruption does not seem essential for attenuation, as it did not occur in the vaccine strain. The sequence spanning genes $\mathrm{m} 137 \mathrm{R} / \mathrm{m} 138 \mathrm{~L}$ of the vaccine strain displayed $100 \%$ nucleotide indentity with "Lausanne". This is rather unexpected, as the sequence comparison with the "MSD" strain (Genbank accession no. AF030894), from which the vaccine strain was derived, displayed only $84 \%$ nucleotide identity to strain "Lausanne". The vaccine strain has a long history of cell culture passaging, and it is thus very difficult to rule out possible cross-contaminations with "Lausanne"-derived isolates or strains at any point.

Altogether, these results support those obtained with specific gene knockout viruses, in that various disruptions, on their own or in synergy, may affect virulence of myxoma viruses (Johnston and McFadden, 2003; Stanford et al., 2007; Willer et al., 1999). Further field strains should 
be analysed to assess the frequency of single base substitutions and indels as well as their importance in reflecting viral evolutionary processes, also considering that misincorporations due to polymerase infidelity (in vivo and in vitro) may account for some of the observed differences between strains. Although focussing on only small parts of the viral genome, this study supports the relatively high degree of genetic stability of myxoma field strains over the past five decades (Saint et al., 2001; Morales et al., 2008). Based on our findings it is difficult to identify unique single gene markers of virus attenuation or evolution, indicating that analyses of larger portions of the genome are required.

\section{Acknowledgements}

This study was supported by the Foundation for Science and Technology Portugal: Project POCTI/BIA-BDE/61553/ 2004 and grants SFRH/BD/31093/2006, SFRH/BD/31048/ 2006, SFRH/BPD $/ 27021 / 2006$ to A.M., J.A. and P.J.E., respectively. Our thanks go to IDT Biologika $\mathrm{GmbH}$, Dessau, Germany, in particular to Dr. Neubert for the permission to use the vaccine strain "MAV" and for supplying information on its origin, and to the FriedrichLoeffler-Institut, Bundesforschungsinstitut für Tiergesundheit, Insel Riems, Germany, in particular to Dr. Dauber and Dr. Riebe, for supplying the RK-13 cells and the abovementioned myxoma vaccine strain. Our thanks also go to Dr. S. Bertagnoli, École Nationale Veterinaire, Toulouse, France, for the primers and protocol for amplifying the thymidine kinase gene of myxoma virus. We also thank the National Laboratory for Veterinary Investigation (LNIV, Delegação do Norte) for infrastructural support.

\section{References}

Bárcena, J., Pagès-Manté, A., March, R., Morales, M., Ramírez, M.A., Sánchez-Vizcaíno, J.M., Torres, J.M., 2000. Isolation of an attenuated myxoma virus field strain that can confer protection against myxomatosis on contacts of vaccinates. Arch. Virol. 146, 759-771.

Best, S.M., Kerr, P.J., 2000. Coevolution of host and virus: the pathogenesis of virulent and attenuated strains of myxoma virus in resistant and susceptible European rabbits. Virology 267, 36-48.
Best, S.M., Collins, S.V., Kerr, P.J., 2000. Coevolution of host and virus cellular localization of virus in myxoma virus infection of resistant and susceptible European rabbits. Virology 277, 76-91.

Bratke, K.A., McLysaght, A., 2008. Identification of multiple independent horizontal gene transfers into poxviruses using a comparative genomics approach. BMC Evol. Biol. 8, 67-70.

Cameron, C., Hota-Mitchell, S., Chen, L., Barrett, J., Cao, J.X., Macaulay, C., Willer, D., Evans, D., McFadden, G., 1999. The complete DNA sequence of myxoma virus. Virology 264, 298-318.

Fenner, F., Ross, J., 1994. Myxomatosis. In: Thompson, H.V., King, C.M. (Eds.), The European Rabbit. The History and Biology of a Successful Colonizer. Oxford University Press, Oxford, pp. 205-239.

Gorski, J., Mizak, B., Chrobocinska, M., 1994. Control of rabbit myxomatosis in Poland. OIE Rev. Sci. Technol. 13, 869-879.

Gubser, C., Hué, S., Kellam, P., Smith, G.L., 2004. Poxvirus genomes: a phylogenetic analysis. J. Gen. Virol. 85, 105-117.

Hall, T.A., 1999. BioEdit: a user-friendly biological sequence alignment editor and analysis program for Windows 95/98/NT. Nucl. Acids Symp. Ser. 41, 95-98.

Hughes, A.L., Friedmann, R., 2005. Poxvirus genome evolution by gene gain and loss. Mol. Phylogenet. Evol. 35, 186-195.

Jackson, R.J., Hall, D.F., Kerr, P.J., 1999. Myxoma virus encodes an alpha 2,3-sialyltransferase that enhances virulence. J. Virol. 73, 2376-2384

Johnston, J.B., McFadden, G., 2003. Poxvirus immunomodulatory strategies: current perspectives. J. Virol. 77, 6093-6100.

Kritas, S.K., Dovas, C.I., Fortomaris, P., Petridou, E., Farsang, A., Koptopoulos, G., 2008. A pathogenic myxoma virus in vaccinated and nonvaccinated commercial rabbits. Res. Vet. Sci. 85, 622-624.

Labudovic, A., Perkins, H., Van Leeuwen, B., Kerr, P., 2004. Sequence mapping of the Californian MSW strain of Myxoma virus. Arch. Virol. 149, 553-570.

Marlier, D., Cassart, D., Boucrout-Baralon, C., Coignoul, F., Vindevogel, H., 1999. Experimental infection of specific pathogen-free New Zealand White rabbits with five strains of amyxomatous myxoma virus. J. Comp. Pathol. 121, 369-384.

Mckercher, D.G., Saito, J., 1964. An attenuated live virus vaccine for myxomatosis. Nature 202, 933-934.

Morales, M., Ramirez, M.A., Cano, M.J., Párraga, M., Castilla, J., PérezOrdoyo, L.I., Torres, J.M., Barcena, J., 2008. Genome comparison of a non-pathogenic myxoma virus field strain with its ancestor the virulent Lausanne strain. J. Virol. doi:10.1128/JVI.02189-08.

Saint, K.M., French, N., Kerr, P., 2001. Genetic variation in Australian isolates of myxoma virus: an evolutionary and epidemiological study. Arch. Virol. 146, 1105-1123.

Stanford, M.M., Werden, S.J., McFadden, G., 2007. Myxoma virus in the European rabbit: interactions between the virus and its susceptible host. Vet. Res. 38, 299-318.

Willer, D.O., McFadden, G., Evans, D.H., 1999. The complete genome sequence of shope (rabbit) fibroma virus. Virology 264, 319-343.

Xing, K., Deng, R., Wang, J., Feng, J., Huang, M., Wang, X., 2006. Genomebased phylogeny of poxvirus. Intervirology 49, 207-214.

Zúñiga, M.C., 2002. A pox on thee! Manipulation of the host immune system by myxoma virus and implications for viral-host co-adaptation. Review Virus Res. 88, 17-33. 